\title{
SMOKING PREVENTION ACTIVITIES AT THE THIRD FACULTY OF MEDICINE OF CHARLES UNIVERSITY IN PRAGUE, CZECH REPUBLIC
}

\author{
Dagmar Schneidrová1, Tereza Kopřivová Herotová1, Magdaléna Šustková2 \\ 'Department of Child and Youth Health, Third Faculty of Medicine, Charles University, Prague, Czech Republic \\ ${ }^{2}$ Department of Pharmacology, Third Faculty of Medicine, Charles University, Prague, Czech Republic
}

In recent years, the Third Medical Faculty of Charles University in Prague has joined the policy of the World Health Organization (WHO) and European Union in order to prevent and reduce smoking among faculty members and students - future health professionals. The following strategies have been developed in the main areas related to academic life - education, counselling, anti-smoking campaign, research, and organizational measures.

\section{Education - Curriculum}

Topics related to smoking were included into curricula of medical and bachelor studies. Department of Pharmacology presents pharmacological aspects of tobacco dependence in the course on "Mental Disorders" in the 3rd year to all medical students. The department also offers the optional course on "Neurobiology, prevention and treatment of dependences" to about 10 medical students in their 3rd and 4th study year. Within one semester course, one three hours seminar is devoted to smoking. The leading experts in the field are invited to the seminar to discuss the issue with students. The students are invited to work on a proposal of a campaign against smoking in students and health professionals. The department presents a special webpage on dependences, incl. smoking with presentations for students (http://www.lf3. cuni.cz/cs/pracoviste/farmakologie/Neuropsychofarmakologie ).

Department of Child and Youth Health presents the following topics related to smoking - health risks, prevalence, prevention and counselling - in the Module of Preventive Medicine scheduled for the 6th year students and students of Public Health, General Nurse, and Dental Hygienist bachelor studies.

\section{Counselling}

The smoking cessation consultancy was established in the academic year 2010/11 in the Students Counselling Centre run at the Department of Child and Youth Health. The consultancy includes the first contact with a client, a motivation dialogue and behavioural counselling, and support in the process of quitting smoking. Clients needing pharmacological treatment are referred to the specialized Centre for the Treatment of Tobacco Dependence at the Clinic of Pneumology and Chest Surgery of the Third Faculty of Medicine in the Bulovka Teaching Hospital in Prague 8.

\section{Anti-smoking Campaign}

In accordance with the World No Tobacco Day (31 May 2011) the joint art exhibiton of our faculty students and the collaborating secondary school for nurses has been organized with the aim to point out to the serious problem of tobacco dependence in young people. The most impressive piece of art had been selected in order to design a poster to be distributed to other faculties of Charles University and University of Economics in Prague.

This year the World No Tobacco Day was aimed particularly at promotion and implementation of the World Health Organization Framework Convention on Tobacco Control (WHO FCTC) in all 193 WHO member countries. We presented posters on this issue at our faculty. The next World No Tobacco Day campaign is planned to achieve higher participation of students. In last three years, medical students engaged in the IFMSA (International Federation of Medical Students Associations) launched a campaign agaist smoking in the form of a Smoke Free Party (www. smokefreeparty.com/).

\section{Research}

We participated at the data collection for the international WHO survey on smoking prevalence in medical students coordinated by the National Institute of Public Health in Prague. We are planning further to assist the research focused on students' behaviour and attitudes development with regards to smoking throughout the whole course of their medical studies.

\section{Restrictive Measures}

The Third Medical Faculty and Královské Vinohrady Teaching Hospital have become no smoking workplaces with bans on smoking encompassing all of their institutional areas.

The Code of Ethics of the Student of the Third Faculty of Medicine, Charles University was elaborated and proposed for the public academic discussion by the head of the Department of Ethics and the head of the Academic Senate of the Third Faculty of Medicine. The code includes the paragraph on smoking which states: "The student of the Third Faculty of Medicine is aware that his behaviour and life style has an influence on other students and is not allowed to smoke in places where it is strictly and explicitly forbidden." The students are called to subscribe the code during their inscription to the study. 